\title{
CROSS LAKE
}

Melissa Brown

My grandmother pulls a new nightgown over my head, sends me out into the woods to find my mother. It is early dusk. When I step into the clearing my mother gasps in mock surprise and runs to fold me in her arms. I see my sisters now, sitting in a row on the white benchswing. My grandmother wants her daughter to believe we came into the world this way-dressed and small enough to walk unnoticed between the trees. Snip goes the price tag, our hair in braids and flowers, our thin arms floating toward the beach. 